\title{
An unusual case of posterior reversible encephalopathy syndrome in a patient being weaned from intrathecal morphine
}

This article was published in the following Dove Press journal:

International Medical Case Reports Journal

17 May 2016

Number of times this article has been viewed

\author{
Jasper Van Aalst' \\ Onno P Teernstra' \\ Wim E Weber ${ }^{2}$ \\ Kim Rijkers ${ }^{3}$ \\ 'Department of Neurosurgery, \\ 2Department of Neurology, \\ Maastricht University Medical \\ Center+, Maastricht, ${ }^{3}$ Department of \\ Neurosurgery, Zuyderland Medical \\ Center, Heerlen, the Netherlands
}

\begin{abstract}
Posterior reversible encephalopathy syndrome (PRES) is a clinicoradiological entity based on clinical signs, including headache, visual abnormalities, and seizures, and radiological abnormalities mostly consisting of vasogenic brain edema predominantly in the posterior parietal-temporal-occipital regions. PRES typically develops in the setting of a significant "systemic process", including preeclampsia, transplantation, infection/sepsis/shock, autoimmune disease, and cancer chemotherapy, in which hypertension often plays an important role. We present a case of PRES in a 63-year-old female patient with an infected intrathecal morphine pump on a cocktail of antibiotics, morphine, clonidine, diazepam, and amitriptyline. It is the first PRES case in a chronic pain patient, which illustrates that PRES can occur in the absence of any of the established risk factors. We hypothesize it may have been caused by antibiotic treatment in our patient.
\end{abstract}

Keywords: PRES, intrathecal morphine, neuropathic pain

\section{Introduction}

Posterior reversible encephalopathy syndrome (PRES) is a clinicoradiological entity first described by Hinchey et $\mathrm{al}^{1}$ in 1996 who called it reversible posterior leukoencephalopathy syndrome. It was renamed PRES by Casey et $\mathrm{al}^{2}$ in 2000 to stress the involvement of both white and gray matter. The diagnosis is based on clinical signs, including headache, decreased alertness, altered mental function, visual abnormalities, and seizures, and radiological abnormalities mostly consisting of vasogenic brain edema, predominantly in the posterior parietal-temporal-occipital regions. Brain edema results from endothelial dysfunction. PRES typically develops in the setting of a significant "systemic process", including preeclampsia, transplantation, infection/sepsis/ shock, autoimmune disease, and cancer chemotherapy. ${ }^{3-5}$ Hypertension has received much attention over the years in explaining the pathophysiology of PRES, but since hypertension is absent in $20 \%-30 \%$ of PRES cases, controversy exists regarding the question whether the hypertension-hyperperfusion theory or vasoconstrictionhypoperfusion theory covers the pathophysiology best. ${ }^{6}$ Symptoms will improve with strict control of blood pressure, and with removal of potential causes, such as cytotoxic or immunosuppressive drugs.

We present a PRES case without hypertension in a 63-year-old female patient with an infected intrathecal morphine pump on antibiotics, morphine, clonidine, diazepam, and amitriptyline. This case is unique because the development of PRES in this case cannot be explained by either the hypertension-hyperperfusion theory or
Correspondence: Kim Rijkers

Department of Neurosurgery, Zuyderland Medical Center, PO Box 4446, 640 I CX Heerlen, the Netherlands

Tel +3I 455766652

Email kimrijkers@gmail.com
International Medical Case Reports Journal 2016:9 II7-120

(c) (1) (8) ๑ 2016 Van Aalst et al. This work is published and licensed by Dove Medical Press Limited. The full terms of this license are avalable at https://www.dovepress.com/terms. cc) you herbby accept the Terms. Non-commercial uses of the work are permitted without any further permisision from Dove Medical Press Limited, provided the work is properly attributed. For permision for commercial use of this work, please see paragraphs 4.2 and 5 of our Terms (https://www.dovepress.com/terms.php).

\section{7}

Dovepress

http://dx.doi.org/10.2147/IMCRJ.S98569 
the vasoconstriction-hypoperfusion theory. Perhaps another, yet unidentified mechanism causing endothelial dysfunction may have caused PRES in this case.

\section{Case}

The patient provided written informed consent for the publication of this paper. Approval of the institutional review board was not obtained as in the Netherlands this is not mandatory in case of a medical case report. A 63-year-old female patient was admitted to our hospital 2 days after fluid started leaking from the subcutaneous pocket of a morphine pump she had to treat chronic stump pain in her left lower (amputated) leg. On admission she was not feeling ill, but since 2 days and on her own initiative, she had been taking amoxicillin/ clavulanic acid 500/125 mg and clindamycin $300 \mathrm{mg}$, both four times daily. The pump delivered $3.5 \mathrm{mg}$ morphine per day intrathecally (equivalent of $1,000 \mathrm{mg}$ orally).

The pump for intrathecal delivery of morphine had been placed in 1999. Twenty years earlier, her left lower leg was amputated because of a postoperative bacterial infection after exostosis resection. Her medical history was otherwise negative; she specifically did not have hypertension or vascular/renal disease.

Despite the absence of systemic signs of infection (negative blood cultures, normal leukocyte count of 4.8-9.8 $\times 10^{9} / \mathrm{L}$, and C-reactive protein [CRP] levels of 1-7 mg/L, while temperature was always between $36^{\circ} \mathrm{C}$ and $37.4^{\circ} \mathrm{C}$, with one peak of $38.9^{\circ} \mathrm{C} 10$ days after a second surgery, when she was already recovering from her PRES), we highly suspected her of an infected pump-pocket. In order to adequately treat this infection and prevent meningitis, we surgically externalized the pump immediately on admission to the hospital, in a procedure under local anesthesia, started with intravenous amoxicillin/clavulanic acid 1,000/200 mg qid, and started to wean her from morphine with steps of $0.5 \mathrm{mg} /$ day. Our aim was to reach an intrathecal morphine dose that was low enough to safely remove the complete pump system.

To overcome the morphine-withdrawal effects on the one side, and to compensate for the loss of pain treatment on the other, she received clonidine orally ( $0.15 \mathrm{mg}$ tid), oxycodon orally (OxyContin $20 \mathrm{mg}$ qid), and fentanyl transcutaneously (Durogesic, $100 \mu \mathrm{g} / \mathrm{h}$ ). Diazepam orally ( $5 \mathrm{mg}$ tid) was added after 4 days of morphine withdrawal to treat cramps that emerged in her lower extremities.

On the fifth day after admission, at an intrathecal morphine dose of $0.5 \mathrm{mg} / \mathrm{day}$, she was operated on for the second time, under general anesthesia (sevoflurane, propofol, sufentanil, and rocuronium) to remove the complete system.
Pus cultures from the first surgery (externalization of the pump) as well as cultures from the intrathecal catheter and cerebrospinal fluid taken during this second surgery (removal of the complete system) did not show growth.

As expected, her old stump-pain returned and required more pain medication. Oxycodon was stopped and amitriptyline $25 \mathrm{mg}$ od was added.

Around this time, she started to become lethargic and somnolent. We presumed this to be medication side effects and lowered her dose of amitriptyline to $10 \mathrm{mg} /$ day, but when she started to complain of visual disturbances as well, the neurologist was consulted and magnetic resonance imaging (MRI) was performed. She was diagnosed with cortical blindness, while MRI revealed bilateral occipital vasogenic edema (Figure 1A and B), and the diagnosis of PRES was made. No hypertension was present at that time nor had been present during her hospital stay. We hypothesized that her PRES was caused by the cocktail of medication she was receiving, and started to withdraw her from all medication, including antibiotics. One day later, she developed seizures and a leftsided hemiparesis. Seizures were treated with levetiracetam orally (500 mg bid), while other medications were further withdrawn. During the following days, her visual disturbances and consciousness improved to normal levels, while the hemiparesis improved more slowly. Follow-up MRI showed a normal aspect of both occipital lobes (Figure 1C and D). When the PRES symptoms lessened, stump pain worsened and required medication, which was carefully, and at a low dose, restarted. Four weeks later, she was referred to a rehabilitation clinic where she further improved to premorbid levels. At that time, she was taking methadon ( $5 \mathrm{mg}$ bid), gabapentin (300 $\mathrm{mg}$ tid), baclofen (5 mg tid), amitriptyline (10 mg od and $35 \mathrm{mg}$ od), and levetiracetam (500 mg bid).

\section{Discussion}

Our case is a typical PRES with regard to the clinical presentation and radiological abnormalities, with lethargy, somnolence, cortical blindness, seizures, and vasogenic edema in the occipital lobes on MRI. The left-sided hemiparesis is not typical PRES. MRI did not explain this clinical finding, but we may have missed a coexisting reversible cerebral vasoconstriction syndrome in our patient. For this diagnosis that has been associated with PRES in a number of case reports, vascular imaging is necessary. ${ }^{7}$ In our patient, magnetic resonance angiogram (MRA) was performed and was without abnormalities (Figure 1).

Even though clinically typical, our case is atypical with regard to the cause. 


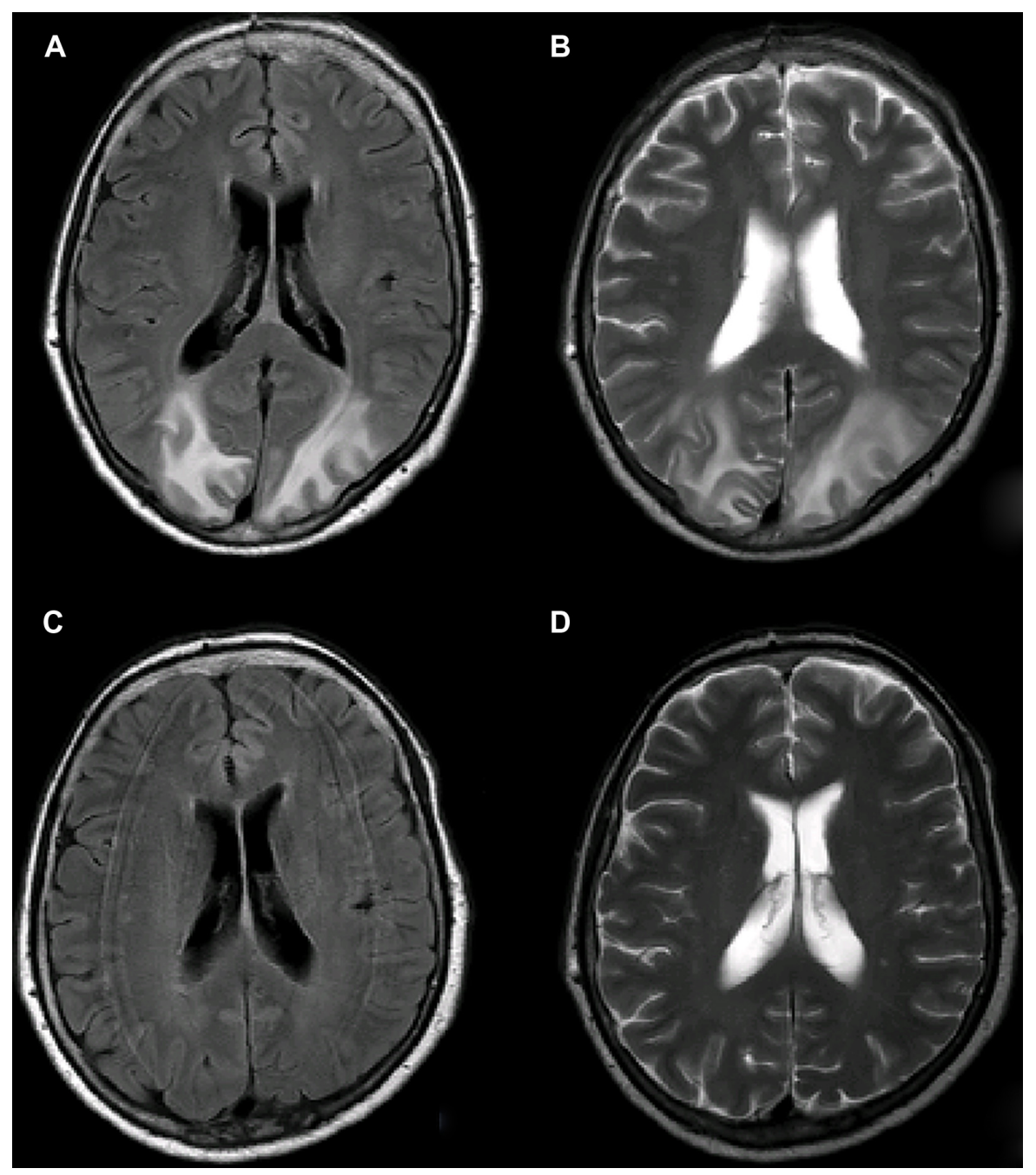

Figure I Axial brain MR images.

Notes: Flair (A and $\mathbf{C}$ ) and T2-weighted (B and $\mathbf{D})$ MR images at the time of PRES diagnosis $(\mathbf{A}$ and $\mathbf{B})$ and 4 weeks later (C and $\mathbf{D})$.

Abbreviations: MR, magnetic resonance; PRES, posterior reversible encephalopathy syndrome.

The cause of PRES has not been entirely elucidated but is thought to result from a brain-capillary leak syndrome. This can be caused by an acute raise in blood pressure, leading to failed autoregulation and, ultimately, to hyperperfusion (hypertension-hyperperfusion theory). ${ }^{6} \mathrm{~A}$ parallel hypothesis on the other hand suggests that vasoconstriction occurs as a response to hypertension, leading to reduced brain perfusion, ischemia, and vasogenic edema (vasoconstriction-hypoperfusion theory). ${ }^{6}$ In our case, hypertension was not present. Our patient's blood pressure was monitored three times daily before PRES onset, and even more frequently after she was diagnosed with PRES. The hypertension-hyperperfusion theory can therefore not explain the development of PRES in our patient.

The vasoconstriction-hypoperfusion theory could play a role, but mainly explains PRES in severe, systemically ill patients, for instance, suffering from severe infection and sepsis, which are acknowledged causes of PRES, also related to endotoxin-induced endothelial dysfunction. ${ }^{8}$ Our patient has never had clinical or laboratory signs of severe infection.

Endothelial dysfunction and blood-brain barrier leakage in PRES can further be caused by medication and systemic disease. ${ }^{5,8}$ None of our patient's medication has been identified as a cause of PRES. Clonidine has even been used in PRES patients to treat hypertension, while gabapentin has been used to treat PRES-related seizures. ${ }^{9}, 10$ Two case reports have been published in which antibiotic treatments (ciproxin and linezolid) were identified as pharmacotoxic cause of PRES. ${ }^{2,11}$

PRES has been associated with alcohol withdrawal. ${ }^{12}$ Our patient was withdrawn from opiates. The temporal relation of PRES and removal of the opiate pump may suggest a role for opiate withdrawal. 
The second surgical procedure was carried out under general anesthesia. One case of PRES has been described in a patient emerging from anesthesia. ${ }^{13}$ This patient suffered from transient hypertension at that time, which was not observed in our patient.

Although the vast majority of PRES cases published in literature involve systemically ill patients, a single case of "spontaneous" PRES has been published, a severe case with fatal ending. ${ }^{14}$ This case highlights the fact that not all risk factors for the development of PRES have been identified. Endothelial dysfunction most likely caused PRES in this fatal case. Although we have not been able to identify one single agent causing PRES in our case, we suspect that pharmacotoxic effects of augmentin and clindamycin have played an important role. Endothelial dysfunction after augmentin or clindamycin treatment has not been reported in literature, but perhaps individual drug hypersensitivity plays a role in our patient. ${ }^{15}$

\section{Conclusion}

PRES is a rare neurological condition, classically seen in systemically ill patients suffering from acute hypertension, or being on cytotoxic or immunosuppressive drugs. Our case illustrates that it can occur in the absence of any of these risk factors as well. Perhaps, pharmacotoxic side effects of antibiotics can cause PRES as well. Regardless the cause, quick recognition of the clinical syndrome is important, and MRI is mandatory to confirm the diagnosis. PRES symptoms can be fully reversible if the cause is known and treated, but in the absence of a clear cause, PRES can be hard to treat and even be fatal. ${ }^{14}$

\section{Acknowledgments}

The authors would like to thank Prof Dr M Van Kleef and Dr H Moser for their help in clinical decision making in this case. K Rijkers, J Van Aalst, OP Teernstra, and WE Weber have no competing interests, and received no funding for the preparation of this manuscript.

\section{Author contributions}

All authors contributed toward data analysis, drafting and revising the paper and agree to be accountable for all aspects of the work.

International Medical Case Reports Journal

\section{Publish your work in this journal}

The International Medical Case Reports Journal is an international, peer-reviewed open-access journal publishing original case reports from all medical specialties. Previously unpublished medical posters are also accepted relating to any area of clinical or preclinical science. Submissions should not normally exceed 2,000 words or

\section{Disclosure}

The authors report no conflicts of interest in this work.

\section{References}

1. Hinchey J, Chaves C, Appignani B, et al. A reversible posterior leukoencephalopathy syndrome. N Engl J Med. 1996;334(8):494-500.

2. Casey SO, Sampaio RC, Michel E, Truwit CL. Posterior reversible encephalopathy syndrome: utility of fluid-attenuated inversion recovery MR imaging in the detection of cortical and subcortical lesions. AJNR Am J Neuroradiol. 2000;21(7):1199-1206.

3. Fujieda Y, Kataoka H, Odani T, et al. Clinical features of reversible posterior leukoencephalopathy syndrome in patients with systemic lupus erythematosus. Mod Rheumatol. 2011;21(3):276-281.

4. Marrone LC, Gadonski G, Diogo LP, et al. Posterior reversible encephalopathy syndrome: differences between pregnant and nonpregnant patients. Neurol Int. 2014;6(1):5376.

5. Vieillot S, Pouessel D, de Champfleur NM, Becht C, Culine S. Reversible posterior leukoencephalopathy syndrome after carboplatin therapy. Ann Oncol. 2007;18(3):608-609.

6. Bartynski WS. Posterior reversible encephalopathy syndrome, part 1 : fundamental imaging and clinical features. AJNR Am J Neuroradiol. 2008;29(6):1036-1042.

7. Lee WJ, Yeon JY, Jo KI, Kim JS, Hong SC. Reversible cerebral vasoconstrictor syndrome and posterior reversible encephalopathy syndrome presenting with deep intracerebral hemorrhage in young women. J Cerebrovasc Endovasc Neurosurg. 2015;17(3):239-245.

8. Bartynski WS, Boardman JF, Zeigler ZR, Shadduck RK, Lister J. Posterior reversible encephalopathy syndrome in infection, sepsis, and shock. AJNR Am J Neuroradiol. 2006;27(10):2179-2190.

9. Narbone MC, Musolino R, Granata F, Mazzù I, Abbate M, Ferlazzo E. PRES: posterior or potentially reversible encephalopathy syndrome? Neurol Sci. 2006;27(3):187-189.

10. Shepard PW, St Louis EK. Seizure treatment in transplant patients. Curr Treat Options Neurol. 2012;14(4):332-347.

11. Nagel S, Kohrmann M, Huttner HB, Jo KI, Kim JS, Hong SC. Linezolidinduced posterior reversible leukoencephalopathy syndrome. Arch Neurol. 2007;64(5):746-748.

12. Ishikawa H, Natsume N, Matwui K, Tsuda H. Acute alcohol withdrawal accompanied by posterior reversible encephalopathy syndrome. Psychiatry Clin Neurosci. 2013;67(3):189.

13. Inoue S, Kawaguchi M, Furuya H. A case of posterior reversible encephalopathy syndrome after emergence from anesthesia. $J$ Anesth. 2012;26(1):111-114.

14. Golombeck SK, Wessig C, Monoranu CM, et al. Fatal atypical reversible posterior leukoencephalopathy syndrome: a case report. J Med Case Rep. 2013;7(1):14.

15. Karlin E, Phillips E. Genotyping for severe drug hypersensitivity. Curr Allergy Asthma Rep. 2014;14(3):418. manuscript management system is completely online and includes a very quick and fair peer-review system, which is all easy to use. Visit $\mathrm{http}: / /$ www.dovepress.com/testimonials.php to read real quotes from http://www.dovepros
published authors. 